\title{
Is Corporate Social Responsibility possible in the mining sector? Evidence from
}

\section{Catalan companies.}

Carla Vintró, ${ }^{\mathrm{a}, *}$, Jordi Fortuny ${ }^{\mathrm{a}}$, Lluís Sanmiquel ${ }^{\mathrm{b}}$, Modesto Freijo ${ }^{\mathrm{c}}$, Joaquín Edo ${ }^{\mathrm{b}}$

a Department of Business Management, Polytechnic University of Catalonia (UPC), Avenue Bases de Manresa, 61 73, 08242 Manresa (Barcelona), Spain

${ }^{\mathrm{b}}$ Department of Mining Engineering and Natural Resources, Polytechnic University of Catalonia (UPC), Avenue Bases de Manresa, 61-73, 08242 Manresa (Barcelona), Spain

${ }^{\mathrm{c}}$ Department of Electrical Engineering, Polytechnic University of Catalonia (UPC), Avenue Bases de Manresa, 6173, 08242 Manresa (Barcelona), Spain

\begin{abstract}
This paper examines the role and diffusion of corporate social responsibility (CSR) management, especially in relation with the adoption of other management systems, in small and medium sized companies in the surface mining industry in Catalonia (Spain). Specifically, it identifies the most salient CSR practices, procedures and metrics and the profiles of companies more prone to adopt them. To fulfill this aim, a survey has been conducted. Results show that mining companies are familiar with CSR practices, but there is not much formalization of procedures and measurement systems of CSR yet. Results show that the majority of socially responsible practices are related to environmental issues and therefore there is a relation between CSR and the application of environmental management systems. The analysis reveals that the management of CSR activities improves with the diffusion of knowledge on CSR practices. A second survey collected the opinion of professional associations in the sector. Respondents indicate that an improvement in CSR management will lead to a better global competitive position.
\end{abstract}

Keywords: Corporate social responsibility; mining industry; management; Catalonia 


\section{Introduction}

In the global economy, the mining sector plays a fundamental role as it provides vital raw materials and energy for a large number of industries including ceramics, building, electronics, metal, paper, plastics and others. Spain has traditionally been an outstanding European producer of nonferrous and precious metals. According to data from 2009, it was the sixth European producer of sand and gravel for industrial applications and the third producer of gypsum in Europe. Nevertheless, the global economic and financial crisis initiated in 2007 affected the major markets for construction and ceramics and consequently, the consumption of all types of minerals declined. In Spain, the value of mineral output (not including mineral processing) decreased by $20 \%$, from $€ 4,465$ million of marketable production in 2007 to $€ 3,549$ million in 2009 (USGS, 19942009; General Directorate of Mining, 2009).

Catalonia, one of the most industrial communities in Spain, is also one of the regions with a high production of minerals (considering all types of minerals as a whole). Between 2000 and 2007 the production output increased and in 2007 it started to decline as a consequence of the international economic crisis (in spite of the economic situation, Catalonia became the first producer of minerals in Spain in 2009). According to the latest statistics published by the General Directorate of Mining of the Spanish Government, the Catalan sector accounted for almost $16.7 \%$ of the national mineral production with around $€ 600$ million in 2009 , and it employed about 2,692 direct workers and 1,349 indirect workers (General Directorate of Mining, 2000-2009). Amongst the different minerals, quarry products, including ornamental stone, was the second sector in marketable production in Catalonia with about $41 \%$ ( $€ 247$ million) of the total regional production (General Directorate of Mining, 2009). More detailed data 
can be found (in Spanish) on the General Directorate of Mining website (www.mityc.es/energia/mineria).

Mining activities have important economic, environmental, labor and social repercussions on local and global scales (Escanciano et al., 2010). In this sense, the first decade of the 21 st century in particular has seen a renewed debate about mining and its sustainability (Mudd, 2009). This is owing to public concern about its environmental and social impacts (severe land disturbance, off-site impacts, community displacement, and health and safety problems) (Hilson and Murck, 2000; Sánchez, 1998).

Following the Brundtland definition of sustainable development (WCED, 1987), the main challenge for the sector is to demonstrate that, despite the fact that mining is built on the exploitation of non-renewable resources, it contributes to the welfare and wellbeing of the current generation without compromising the quality of life of future generations (Azapagic, 2004), and that companies mind their social dimensions (Solomon et al., 2008).

The mining industry has to deal with these challenges and has to assume responsibilities in local and national development. There is evidence in the literature that since the early 1990s, the mining industry has shown increasing interest in social and environmental issues and it has been seeking ways to enhance its sustainability levels (Hilson and Murck, 2000). Sustainable development and ethical management have been included in the agendas of the mining industry (Cowell et al., 1999), and various national and international initiatives have developed frameworks for sustainability. For instance, the European Union (CEC, 2000) has promoted priorities based on four broad pillars (environmental protection, economic issues, social performance and employment, and research and technological development). Another instance is that the International 
Council on Mining and Metals (ICMM) has formulated 10 basic principles of good practice, including ethical management, sustainable development, and contribution to the social and economic development of local communities (ICMM, 2005).

The adoption of socially responsible practices -i.e. environmental protection; dialogue with stakeholders; community-investment programs; commitment to the rights of employees in the company's policies, etc. (Kapelus, 2002; Wheeler et al., 2002)- helps companies to maintain an image of compromise towards the environment and their stakeholders, and to spearhead the pursuit of a social license to operate, which is aimed to secure the support of local communities (Walker and Howard, 2002). The social dimension, together with the environmental and economic dimensions, shape the triple bottom line (Kleine and Hauff, 2009), which is at the basis of Corporate Social Responsibility (Elkington, 1997).

Corporate Social Responsibility (hereinafter CSR) may be defined as the group of actions which are undertaken by an organization in order to accept the responsibilities resulting from the impact of its activities on society and the environment (ISO, 2010). This new business approach has particular significance in mining activities. As noted by Warhurst (2001), the main environmental disasters and human rights incidents that have increased public concern about CSR over the last 40 years have mainly taken place in the mining and petroleum industries. For the mining industry, "CSR is about balancing the diverse demands of communities and the imperative to protect the environment with the ever present need to make a profit" (Jenkins, 2004).

The debate surrounding CSR in the mining industry has gained considerable attention within the academic community. Different authors have analyzed the CSR strategies adopted in the mining sector globally. For instance, Jenkins (2004) has outlined reasons 
why CSR is important for mining. Warhurst (2001) has concentrated on sustainability issues, and Hamann (2004) has studied the relationship between CSR and stakeholders groups with legitimate interests in the company that include employees, trade unions, suppliers, customers, shareholders, creditors, insurers, local communities, governments and NGOs (Azapagic, 2004)-. Other authors have studied the impact of CSR on local communities (Banks, 2006; Jenkins and Yakovleva, 2006; Kapelus, 2002) and have analyzed the practices involved in different countries (Deegan and Rankin, 1996; Hamann and Kapelus, 2004; Harris, 2007; Yakovleva, 2005). Studies on the adherence of different top mining companies to CSR guidelines (Jenkins and Yakovleva, 2006) have also been published in the literature.

In Western developed countries companies have started to carefully consider the social, ethical and environmental effects of their actions. Many Spanish companies, especially the largest ones, have introduced CSR policies, and the adoption of business ethical practices is increasing (Fernández and Melé, 2005). CSR is also encouraged by the European Union (European Commission, 2011). The aim of this paper is to find out whether the mining sector is also committed to CSR by focusing in the aggregate (such as gravel) mining industry and the ornamental stone (such as marble) quarrying in Catalonia.

Although the voluntary CSR initiatives are varied, many of them relate to the areas of quality, environmental management, and occupational safety (Munashinge and Shearer, 1995); areas which may in turn be managed according to international standards such as ISO 9001 (quality), ISO 14001 (environment) and OHSAS 18001 (health and safety at work), to cite the most common ones. In Europe, and especially in Spain, such standards have been adopted by many companies, from the smallest ones to the largest ones (Casadesus et al., 2008). The success of management systems makes us think of 
them as a means for the introduction of CSR practices, even more when CSR is also supported by international standards (ISO 26000:2010 Guidance for Social Responsibility).

In the next section, the paper explores the current discussions on CSR in the mining industry in order to gain insight into the positive and negative contributions of mining to sustainable development. The research methodology is then introduced. Next, the results obtained are presented. Discussions and conclusions follow.

\section{CSR in the mining industry}

For a long time, mining just consisted in exploiting a region until its natural resources were exhausted and then moving on to exploit another region. There was an uncompromising approach to mining in these areas, meaning that local communities viewed mining activities as an economic engine but also as a threat to the natural surroundings, with environmental effects on the air, water and soil. Currently, there is a greater awareness in sustainable development issues, and even the concern with the commitment to the environment has evolved into a commitment to the community where each company carries out its activities (Blinker, 2009). In this respect, growing regulatory pressure on issues concerning waste, pollution and occupational health and safety in particularly dangerous activities has played an important role. This, together with social and legal demands, has meant that more awareness has been raised with regard to these matters.

The debate surrounding mining activities and sustainable development is now centered on sustainability at the global and national scales (Hilson and Murck, 2000). While some authors depict the positive impacts that mining activities can have (Mikesell, 1994; Walker and Howard, 2002; Wheeler et al., 2002), there is still some kind of 
troublesomeness with the link 'sustainable development and mining'. A major argument against the mining sector contributing to sustainable development is that mineral resources are finite and non-renewable (Cowell et al., 2009) and therefore the opportunities for future generations to access these resources are reduced (WCED, 1987). Moreover, the risk of professional diseases and accidents in mining activities i.e. the recent collapse in Copiapó (Chile, August 2010) and the Sago Mine disaster (United States, January 2006) - has contributed to a questionable reputation for social responsibility (Lambert, 2001; Sandbroke and Mehta, 2002).

Morphological changes in the exploited areas, noise, dust, and surface and groundwater pollution are the main environmental hazards produced by mining operations. Despite the initiatives undertaken at international level to address these problems and the efforts made by some companies, there is still a negative perception of society towards these issues (Evangelinos and Oku, 2006).

On the other hand, primary examples of positive contributions of mining to sustainable development and social management include caring for the country, people and culture. (Howitt, 2001). These incorporate providing employment to residents of local communities (Dorian and Humphreys, 1994), job retraining services (Hilson and Murck, 2000), using local suppliers (Esteves, 2008), re-investing in downstream businesses (Pegg, 2006), and contributing funds to regional developmental projects and key socioeconomic infrastructure such as roads, hospitals, schools and housing (Hilson, 2002).

As stated by Hilson and Murck (2000), the mining industry can contribute to sustainable development by minimizing the environmental and social impacts throughout its life 
cycle, and this is best accomplished through effective CSR management. The authors give some guidance on how to improve the sustainability in mining operations.

Mining activities might be viewed as more socially and environmentally responsible if CSR practices were adopted. In this sense, Mikesell (1994) states that reinvestment practices (i.e. investing the wealth generated in the construction of critical infrastructures for local communities) could contribute to improve the levels of sustainability in the sector. Gibson (2000) suggests that any negative effect should be immediately remediated, which would improve the reputation of mining. Newbold (2003) argues that mining industries should get involved in voluntary programs which are aimed to favor the development of the region where they operate. Walker and Howard (2002) outline that CSR is a helpful conceptual framework to face different challenges: the public opinion (which is more influenced by concerns over environmental and social performance than by performance in product, quality, and safety); the pressure of groups that have negatively targeted the sector at international levels; maintaining a social license to operate; and screening of socially responsible investing funds (Jenkins and Yakovleva, 2006).

Accordingly, community relations have emerged as a strategic consideration for mining companies (Esteves, 2008) and the approach adopted has changed from benefitting local communities to their long-term sustainable development (Van der Veen and McMahon, 2007). Nevertheless, considerations of sustainable development and therefore the expected social commitments may vary between developed and developing countries (Humphreys, 2001). In developing countries mining companies commonly have to shoulder on their own education and health issues, programs to support indigenous people and the construction of basic infrastructure. In developed countries (that is the case of Catalonia) these costs are shared with different contributors. 


\section{Methodology}

The basic information for this work comes from a more extensive study that analyses the application of quality, environmental, occupational health \& safety and CSR management systems in the aggregate mining industry and ornamental stone quarrying in Catalonia.

The research was initiated with the design of a questionnaire, which was the main source for data collection. A pilot-test was conducted within a small number of Catalan mining companies in order to prove viability and to detect difficulties in the interpretation of questions.

The final version of the questionnaire comprised 12 items concerning the diffusion of CSR practices, CSR procedures, CSR measurement systems and CSR management systems, and the perception of companies about the benefits experimented in their business results. Some of the items were open-ended questions, others were multiple choice questions and some used a five point Likert scale.

The target population was identified in the 'Register of Catalan Mining (year 2008)' published by the General Directorate of Mining of the Spanish Government. Although a single company may operate in more than one location, the unit of analysis for this research was the company. The population considered amounted to 202 companies.

All questionnaires were sent by electronic mail and by post and were addressed to the Management Systems Manager or to the Business Manager. A cover letter explaining the purpose of the study and a self-addressed and stamped envelope accompanied the survey questionnaire. To increase the response rate, companies were previously contacted by telephone. After the whole process, the deficiencies detected in the answers were rectified through telephone calls or electronic mail. 
A total of 60 completed responses were received (29.7\% response rate), which reached the targeted overall response rate for a valid assessment since Ortega (1990) observes that response rates of $20 \%$ are common and considered satisfactory for post surveys in Spain. Malhotra and Grover (1998) suggest a response rate of over 20\% for a positive assessment of mail survey results.

The statistical analysis of the data was performed using Minitab v.15.

Table 1 shows the technical record of the study.

Table 1

Technical record of the study.

\begin{tabular}{|c|c|c|}
\hline Population: & \multicolumn{2}{|c|}{202 surface mining companies (147 aggregates; 55 ornamental stone) } \\
\hline Geographical area: & \multicolumn{2}{|l|}{ Catalonia (Spain) } \\
\hline Survey addressed to: & \multicolumn{2}{|c|}{ Management Systems Manager (or Business Manager) } \\
\hline Sample unit: & \multicolumn{2}{|c|}{ Company } \\
\hline Sample size: & \multicolumn{2}{|l|}{202 companies } \\
\hline Response rate: & \multicolumn{2}{|l|}{$29.7 \%$ (60 companies) } \\
\hline \multicolumn{2}{|l|}{ Details } & Total \\
\hline \multicolumn{2}{|c|}{ Companies included in the Register of Catalan Mining (year 2008) } & $202(100 \%)$ \\
\hline \multicolumn{2}{|c|}{ Questionnaires received after the pilot test } & $5(2.5 \%)$ \\
\hline \multicolumn{2}{|c|}{ Questionnaires received after the first mailing } & $30(14.9 \%)$ \\
\hline \multicolumn{2}{|c|}{ Questionnaires received after a reminder } & $10(4.9 \%)$ \\
\hline \multicolumn{2}{|c|}{ Questionnaires received after the second mailing } & $16(7.9 \%)$ \\
\hline \multicolumn{2}{|c|}{ Total number of questionnaires received } & $61(30.2 \%)$ \\
\hline \multicolumn{2}{|c|}{ Non-valid questionnaires } & $1(0.5 \%)$ \\
\hline \multicolumn{2}{|c|}{ Total number of valid questionnaires } & $60(29.7 \%)$ \\
\hline
\end{tabular}

Source: Questionnaire survey

\section{Results and discussion}

\subsection{The companies' profile}

The distribution of the sampled companies by mineral type (aggregate and ornamental stone mining) is indicated in Table 2. Around $90 \%$ of these companies are medium or small sized firms according to the European Union Recommendation 2003/361/EC. The 
quantity of mineral extracted varies from 4,000 to 6.7 million tons a year. These companies mainly concentrate their commercial activity on a national scale.

Table 2

Distribution by type of mineral

\begin{tabular}{llllll}
\hline & \multicolumn{2}{l}{ Size of the company } & & \multirow{2}{*}{ Total } \\
\cline { 2 - 5 } & Micro & Small & Medium & Big & \\
\hline Aggregates & $12(24 \%)$ & $27(55 \%)$ & $6(12 \%)$ & $4(8 \%)$ & $49(100 \%)$ \\
Ornamental Stone & $6(55 \%)$ & $4(36 \%)$ & $0(0 \%)$ & $1(10 \%)$ & $11(100 \%)$ \\
Total & $18(30 \%)$ & $31(52 \%)$ & $6(10 \%)$ & $5(8 \%)$ & $60(100 \%)$ \\
\hline
\end{tabular}

Source: Questionnaire survey

${ }^{a}$ Classification of the European Union Recommendation 2003/361/EC

The literature suggests that larger firms are more likely to be under public scrutiny (Liu and Anbumozhi, 2009) and are generally capable of having superior resources (Spence, 1999). Nevertheless, the study conducted shows that medium and small companies have also undertaken various socially and environmentally responsible actions (we refer the reader to subsequent sections).

\subsection{Management systems}

Management systems are a set of organizational procedures, responsibilities and processes that help to implement corporate policies regarding quality, environment, health and security, etc. Most usual management systems are in accordance with international certifiable standards such as ISO 9001 (product and service quality management system), ISO 14001 (environmental management system) or OHSAS 18001 (occupational health and safety management system).

About $64 \%$ of the surveyed companies described efforts like ISO 9001 certification, ISO 14001 certification or OHSAS 18001 certification to align business practices with 
the needs and expectations of society. The percentages of application of management systems are detailed in Table 3.

Table 3

Management systems implemented

\begin{tabular}{lllll}
\hline \multicolumn{5}{l}{ Management systems } \\
& $\begin{array}{l}\text { Quality } \\
\text { ISO 9001 }\end{array}$ & $\begin{array}{l}\text { Environment } \\
\text { ISO 14001 }\end{array}$ & $\begin{array}{l}\text { Health \& Safety } \\
\text { OHSAS 18001 }\end{array}$ & $\begin{array}{l}\text { CSR } \\
\text { UNE 22480 }\end{array}$ \\
\hline Aggregates (49) & $25(51 \%)$ & $11(22 \%)$ & $2(4 \%)$ & $1(2 \%)$ \\
Ornamental Stone (11) & $4(36 \%)$ & $2(18 \%)$ & $0(0 \%)$ & $0(0 \%)$ \\
Total (60) & $29(48 \%)$ & $13(22 \%)$ & $2(3 \%)$ & $1(2 \%)$ \\
\hline
\end{tabular}

Source: Questionnaire survey

Results show that companies have experience in management systems. The number of certifications has increased throughout time, especially when referring to quality and environmental management systems. Customers' competitive pressure (Brown et al., 1998) in the first case, and growing environmental regulatory pressure (WCED, 1987) in the second case, have contributed to this fact.

Only $3 \%$ of the companies had an OHSAS 18001 system, but $100 \%$ had implemented the 'Safety and Health Document for extractive industries'. In Spain, this is a compulsory document for mining companies and shares many points with occupational health and safety standards.

One out of the sixty surveyed companies had a CSR management system certificate. It is a small-sized company and it has implemented the UNE 22480 standard (a Spanish norm for sustainable mining management). The company is the first sustainable stone quarry in Catalonia and the third one in Spain to obtain the certificate from AENOR (Spanish Association for Standardization and Certification). 
Some companies admitted the existence of certain difficulties in the implementation of management systems. For instance, a surveyed Manager asserted in a questionnaire that:

'We have always done the same and done it in the same way. Why should we break away from the existent business culture?'

On the other hand, the high levels of bureaucratization within the sector (administrative concessions, prospecting permits, etc.) have commonly caused an aversion to the implementation of any management system. For instance, a respondent noted:

'Why implement an environmental management system when different institutions like the Catalan Agency of Water (ACA) or the Nature Protection Service (SEPRONA) inspect the company each year? Under this situation, it is difficult to urge the company to implement a management system'.

In spite of these complaints, companies showed an incipient interest in management systems. Most companies (64\% of companies that had implemented the ISO 9001 standard, $50 \%$ for OHSAS 18001, and $23 \%$ for ISO 14001) admitted that the implementation of management systems had conveyed some benefits (i.e. easier management of resources and processes). A mine site manager made the following observation:

'Management systems are useful and can significantly benefit business results as long as they are supported and promoted by the CEO of the company. Otherwise, they are just a useless waste of time and resources'.

\subsection{CSR practices}

Around $63 \%$ of the mining companies $(65 \%$ aggregate mines and $55 \%$ ornamental stone quarries) participating in the study stated that they knew or had heard about CSR 
management systems (Table 4). This result led us to high expectations regarding the implementation of CSR practices. Nevertheless, $52 \%$ of the companies (51\% aggregate mines and 55\% ornamental stone quarries) did not know about the UNE 22480 standard for sustainable mining management. This is a negative result because that standard is sector-specific. In this sense, the actions promoted by public administrations and professional associations may play a prominent role in the diffusion of CSR. Similar conclusions were published in previous studies. For example, Nijkamp et al. (1999) already considered that public administrations should take a leading role in the promotion of environmental actions.

Table 4

CSR management systems diffusion

\begin{tabular}{|c|c|c|c|c|}
\hline \multirow[t]{2}{*}{ "Do you know...?" } & \multicolumn{2}{|c|}{ CSR management systems } & \multicolumn{2}{|c|}{ UNE 22480 standard } \\
\hline & Aggregates & Ornamental stone & Aggregates & Ornamental stone \\
\hline Yes & $32(65 \%)$ & $6(55 \%)$ & $24(49 \%)$ & $5(45 \%)$ \\
\hline No & $17(35 \%)$ & $5(45 \%)$ & $25(51 \%)$ & $6(55 \%)$ \\
\hline Total & $49(100 \%)$ & $11(100 \%)$ & $49(100 \%)$ & $11(100 \%)$ \\
\hline
\end{tabular}

Source: Questionnaire survey

We examined the diffusion of CSR practices. Respondents were required to indicate which of the eight practices detailed in the questionnaire their companies had implemented (see Table 5). Around $70 \%$ of the companies had implemented at least three different CSR practices and $13 \%$ had applied six or more CSR practices. This is a positive result and it may even be improved in the future. 
Table 5

Distribution of CSR practices

\begin{tabular}{llll}
\hline \multirow{2}{*}{ CSR management practices } & \multicolumn{2}{l}{ Companies by mineral type } & \\
\cline { 2 - 3 } & Aggregates & Ornamental stone & Total \\
\hline Restoration plans in mine closure & $49(100 \%)$ & $11(100 \%)$ & $60(100 \%)$ \\
Codes of conduct & $34(69 \%)$ & $10(91 \%)$ & $44(73 \%)$ \\
Energy sources consumption control & $27(55 \%)$ & $4(36 \%)$ & $31(52 \%)$ \\
Mining source reduction & $25(51 \%)$ & $5(45 \%)$ & $30(50 \%)$ \\
Information transparency & $21(43 \%)$ & $3(27 \%)$ & $24(40 \%)$ \\
Promotion of local communities & $17(35 \%)$ & $0(0 \%)$ & $17(28 \%)$ \\
Professional career & $4(8 \%)$ & $2(18 \%)$ & $6(10 \%)$ \\
Cooperation with humanitarian NGOs & $1(2 \%)$ & $1(9 \%)$ & $2(3 \%)$ \\
Cooperation with other NGOs & $2(4 \%)$ & $0(0 \%)$ & $2(3 \%)$ \\
Cooperation with environmental NGOs & $1(2 \%)$ & $0(0 \%)$ & $1(2 \%)$ \\
Cooperation with development aid NGOs & $0(0 \%)$ & $0(0 \%)$ & $0(0 \%)$ \\
Total companies & $49(100 \%)$ & $11(100 \%)$ & $60(100 \%)$ \\
\hline
\end{tabular}

Source: Questionnaire survey

The results in Table 5 imply that companies have committed themselves to ethical and sustainable issues. For example, one of the surveyed companies asserted that:

'We understand the effect our mining activities have on the environment, and we are aware of the need to implement sustainable working criteria in all areas'

We combined the eight CSR practices into three main groups according to the three vertices of the CSR Munasinghe triangle (environmental, social and economic criteria): CSR management practices linked to environmental management (Figure 1), CSR management practices linked to human resources management (Figure 2), and CSR management practices linked to sustainable administration of funds (Figure 3).

Aggregate mining companies accounted for higher percentages of environmental practices and sustainable administration of funds; whereas ornamental stone quarrying 

practices.

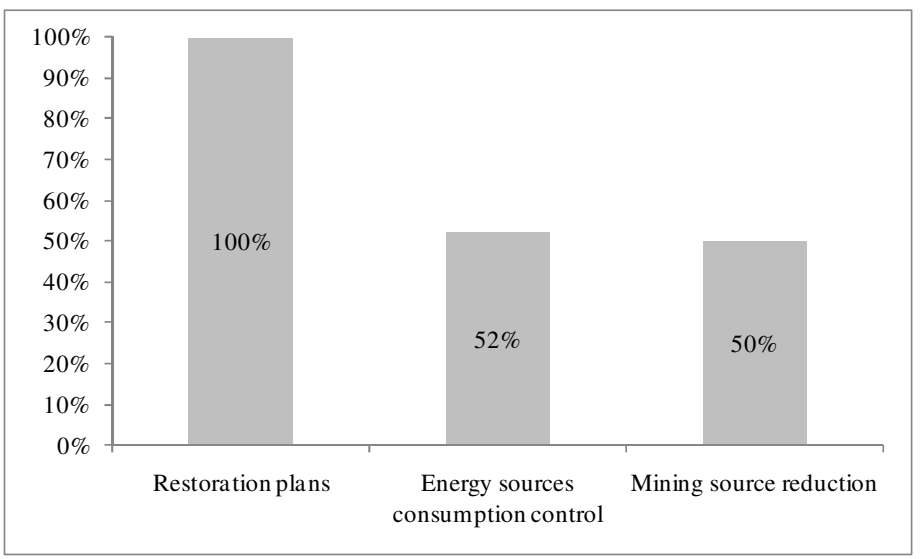

Fig. 1. CSR management practices linked to environmental management.

Source: Questionnaire survey

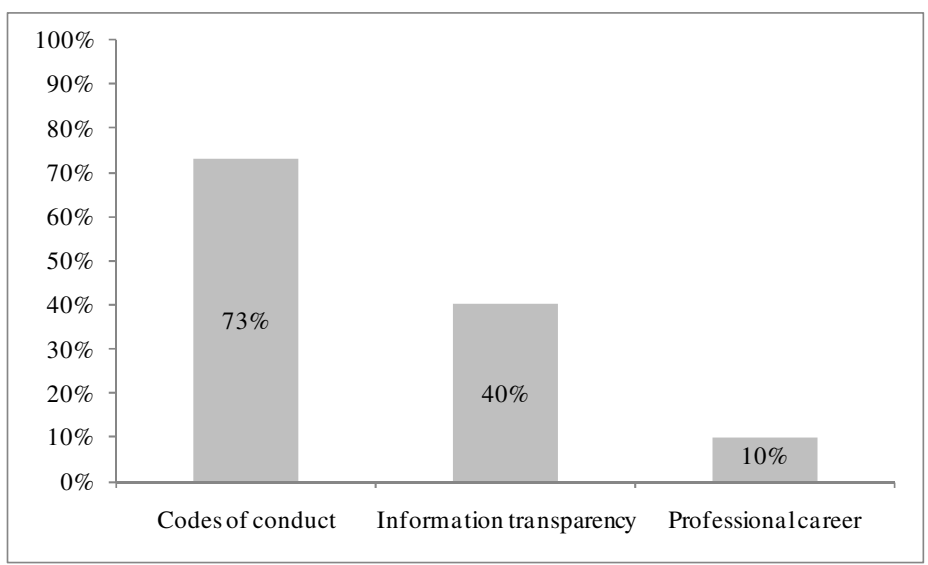

Fig. 2. CSR management practices linked to human resources management.

Source: Questionnaire survey

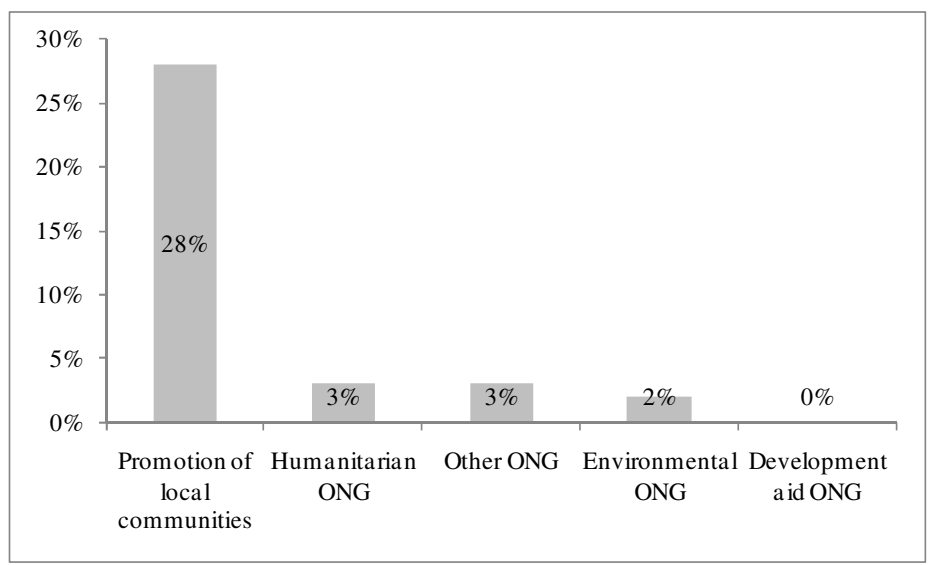

Fig. 3. CSR management practices linked to sustainable administration of funds.

Source: Questionnaire survey 
Global results (figures 1-2-3) imply that CSR environmental practices (such as restoration plans, mining source reduction and control of energy consumption) are more widespread than social actions (i.e. cooperation with non-governmental organizations and promotion of local communities). While this difference could be attributed to a number of reasons, a core factor may be:

'The high impact of the mining industry on the environment, which is probably the most perceived threat from mineral extraction activities' (observation made by a respondent in one of the questionnaires).

\subsection{CSR procedures and measurement systems}

A procedure is a specified way to carry out an activity or process. Procedures describe the aim of the process and its necessary steps, technical elements, technical conditions and human resources. Procedures are included within the documentation of quality, environmental and occupational health and safety management systems. In the same way, procedures are an essential element of CSR management systems.

We examined the application of CSR procedures and measurement systems in the mining companies. Variables "CSR procedures" and "CSR measurement systems" were measured with five point (1-5) Likert scales in order to evaluate their application. Descriptive statistics for these variables are shown in Table 6. The mean values (1.917 for CSR procedures and 1.750 for CSR measurement systems), which are significantly lower than the central point (3) of the scale at the 0.05 level, suggest that management of CSR practices should be improved. Aggregate mining companies registered higher levels of application of both CSR procedures and measurement systems than ornamental stone quarries. 
Table 6

Statistical summary of the variables "CSR procedures" and "CSR measurement systems"

\begin{tabular}{llllll}
\hline Variable name & Obs. & Mean & Std. dev. & Skewness & Kurtosis \\
\hline CSR procedures & 60 & 1.917 & 1.124 & 1.21 & 0.60 \\
CSR management systems & 60 & 1.750 & 1.083 & 1.43 & 1.35 \\
\hline
\end{tabular}

Source: Questionnaire survey

The results obtained in the questionnaire survey indicate a poor application of CSR procedures (Table 7). While mining companies were used to CSR practices, around $47 \%$ (43\% aggregate mines and $64 \%$ ornamental stone quarries) did not have written CSR procedures for these practices. Only $3 \%$ of the respondents (4\% aggregate mines and $0 \%$ ornamental stone quarries) had written procedures for all the CSR activities implemented.

Table 7

CSR procedures diffusion

\begin{tabular}{|c|c|c|c|}
\hline \multirow{2}{*}{$\begin{array}{l}\text { Has the company } \\
\text { written CSR procedures? }\end{array}$} & \multicolumn{2}{|c|}{ Companies by mineral type } & \multirow[b]{2}{*}{ Total } \\
\hline & Aggregates & Ornamental stone & \\
\hline 1: For none of the practices & $21(43 \%)$ & $7(64 \%)$ & $28(47 \%)$ \\
\hline 2: For $25 \%$ of the practices & $15(31 \%)$ & $4(36 \%)$ & $19(32 \%)$ \\
\hline 3: For $50 \%$ of the practices & $5(10 \%)$ & $0(0 \%)$ & $5(8 \%)$ \\
\hline 4: For $75 \%$ of the practices & $6(12 \%)$ & $0(0 \%)$ & $6(10 \%)$ \\
\hline 5: For all the practices & $2(4 \%)$ & $0(0 \%)$ & $2(3 \%)$ \\
\hline Total companies & $49(100 \%)$ & $11(100 \%)$ & $60(100 \%)$ \\
\hline
\end{tabular}

Source: Questionnaire survey

One of the surveyed companies that had implemented CSR procedures and control systems declared in the questionnaire:

'We take account of possible effects of our activities, and we adopt a variety of measures to control work and develop periodic plans for restoring the initial conditions'. 
The percentage of CSR measurement systems implementation is relatively low, too (Table 8). More than half of the surveyed companies (58\%) did not use measurement systems to track the CSR results. Some respondents argued that this low percentage could be mainly attributed to the newness of CSR as a guideline for company strategy. However, it is important to note that, in the literature, there are some proposals of CSR indicators for mining activities. For example, Azapagic (2004) defined a set of sustainable development indicators for the mining industry based on a modified set of global reporting initiative (GRI) indicators. Worrall et al. (2009) have developed a sustainability criteria and indicators framework for legacy mine land. Vintró and Comajuncosa (2010) presented another performance chart intended as an internal measure of continuous improvement in CSR for mining companies. Different bodies have also proposed systems for the measurement of CSR results in the mining industry (i.e. GRI Mining \& Metals Sector Supplement, UNE 22470 Sustainable mining indicators -pilot version).

Table 8

CSR measurement systems diffusion

\begin{tabular}{llll}
\hline $\begin{array}{l}\text { Does the company use any metrics } \\
\text { in CSR management? }\end{array}$ & \multicolumn{2}{l}{ Companies by mineral type } & \multirow{2}{*}{ Total } \\
\cline { 2 - 3 } & Aggregates & Ornamental stone & $35(59 \%)$ \\
\hline 1: For none of the practices & $26(53 \%)$ & $9(82 \%)$ & $12(20 \%)$ \\
2: For $25 \%$ of the practices & $10(21 \%)$ & $2(18 \%)$ & $8(13 \%)$ \\
3: For $50 \%$ of the practices & $8(16 \%)$ & $0(0 \%)$ & $3(5 \%)$ \\
4: For $75 \%$ of the practices & $3(6 \%)$ & $0(0 \%)$ & $2(3 \%)$ \\
5: For all the practices & $2(4 \%)$ & $0(0 \%)$ & $60(100 \%)$ \\
Total companies & & & $11(100 \%)$ \\
\hline Source: Questionnaire survey & $49(100 \%)$ & &
\end{tabular}

\subsection{Perceived CSR utility}

Respondents were required to assert whether CSR practices were contributing to improve business results or whether they were not. Variable "perceived CSR utility" 
was measured with a five point (1-5) Likert scale. Around $23 \%$ of the companies $(25 \%$ aggregate mines and $18 \%$ ornamental stone quarries) perceived a positive impact (punctuations 4 or 5 in the Likert 1-5 scale). The mean 2.9 (very close to 3, the central value in the interval) indicates that the null hypothesis cannot be rejected $\left(H_{0}: \mu=3 ; p\right.$ value $>0.05$ ), thus the average perceived CSR utility is neutral (neither positive nor negative). Results are detailed in Table 9.

Table 9

Perceived CSR utility

\begin{tabular}{lllll}
\hline \multirow{2}{*}{$\begin{array}{l}\text { Contribution of } \begin{array}{l}\text { to business results } \\
\text { 1: Negative }\end{array} \\
\text { 2: Slightly negative }\end{array}$} & management & \multicolumn{2}{l}{ Companies by mineral type } & \\
\cline { 2 - 3 } & Aggregates & Ornamental stone & Total \\
\hline 3: Neutral & $5(10 \%)$ & $2(18 \%)$ & $7(12 \%)$ \\
4: Slightly positive & $5(10 \%)$ & $1(9 \%)$ & $6(10 \%)$ \\
5: Positive & $20(41 \%)$ & $6(55 \%)$ & $26(43 \%)$ \\
n/a & $8(17 \%)$ & $2(18 \%)$ & $10(17 \%)$ \\
Total companies & $4(8 \%)$ & $0(0 \%)$ & $4(6 \%)$ \\
\hline
\end{tabular}

Source: Questionnaire survey

Cross tabulation tables were used in this study to explore the relationship between different pairs of variables: number of CSR practices vs. CSR procedures; CSR procedures vs. CSR measurement system; CSR procedures vs. perceived CSR utility. Spearman rank correlation coefficient and measures of concordance were used in the analysis. The results obtained are summarized in Table 10. 
Table 10

Cross tabulation analysis

\begin{tabular}{|c|c|c|}
\hline \multicolumn{3}{|l|}{ Results $^{\text {a }}$} \\
\hline & \multicolumn{2}{|c|}{ Pair of variables: number of CSR practices - CSR procedures } \\
\hline & Spearman rank correlation: & 0.539 \\
\hline & \multicolumn{2}{|l|}{ Measures of concordance (p-value: 0.000 ) } \\
\hline & Kendall's tau-b & 0.465 \\
\hline & Kendall's tau-c & 0.424 \\
\hline & Somers' d (number of CSR practices) & 0.511 \\
\hline & Somers' d (CSR procedures) & 0.424 \\
\hline & Gamma & 0.606 \\
\hline & \multicolumn{2}{|c|}{ Pair of variables: CSR procedures - CSR measurement systems } \\
\hline & Spearman rank correlation: & 0.788 \\
\hline & \multicolumn{2}{|l|}{ Measures of concordance: } \\
\hline & Kendall's tau-b & 0.752 \\
\hline & Kendall's tau-c & 0.592 \\
\hline & Somers' d (CSR procedures) & 0.792 \\
\hline & Somers' d (CSR measurement systems) & 0.714 \\
\hline & Gamma & 0.928 \\
\hline & \multicolumn{2}{|c|}{ Pair of variables: CSR procedures - perceived CSR utility } \\
\hline & Spearman rank correlation: & 0.379 \\
\hline & \multicolumn{2}{|l|}{ Measures of concordance: } \\
\hline & Kendall's tau-b & 0.329 \\
\hline & Kendall's tau-c & 0.280 \\
\hline & Somers' d (CSR procedures) & 0.326 \\
\hline & Somers' d (perceived CSR utility) & 0.331 \\
\hline & Gamma & 0.449 \\
\hline
\end{tabular}

Source: Questionnaire survey

${ }^{\text {a }}$ Significant at the 0.01 level

The variable "number of CSR practices" is significantly and positively associated with the variable "CSR procedures" at $\mathrm{p}<0.01$. Another variable that shows a positive correlation (p-value<0.01) with "CSR procedures" is "CSR measurement systems".

The "perceived CSR utility" appears in a weakly positive relationship with "CSR procedures" with significance at the 0.01 level. This result means that the more CSR procedures are implemented, the higher CSR utility the company perceives. 


\subsection{Opinion of professional associations}

We also surveyed 16 professional associations that are knowledgeable about the sector as a whole. They were required to answer a questionnaire about CSR management in the mining industry (18 questions on a five point (1-5) Likert scale).

Results indicate that the core motivation for mining companies in the implementation of CSR management systems was the search for brand image enhancement. The surveyed professional associations also noted that companies should improve the way they manage CSR. They expressed that the main barrier to the implementation of CSR management activities was the lack of economic resources, especially for small and medium scale firms, which is the profile of the majority of mining companies in the sample. In this respect, the Spanish public administration has promoted different actions. For example it launched a campaign of subsidies called "RSE-PYME" (CSR in small and medium size enterprises) to promote the implementation and development of CSR activities for fiscal year 2010.

The opinions expressed by professional associations match the responses of mining companies.

The statistical summary is detailed in Table11.

Table 11

Statistical summary of Professional Associations survey

\begin{tabular}{lccccc}
\hline CSR management & Obs. & Mean & Std. dev. & Skewness & Kurtosis \\
\hline $\begin{array}{l}\text { Core motivator factor } \\
\text { Brand image enhancement }\end{array}$ & 16 & 3.250 & 0.775 & -0.49 & -1.06 \\
\hline $\begin{array}{l}\text { Main barrier } \\
\text { Lack of economic resources }\end{array}$ & 16 & 3.813 & 1.328 & -1.17 & 0.73 \\
\hline $\begin{array}{l}\text { Perceived level of CSR commitment } \\
\text { in mining companies }\end{array}$ & 16 & 2.625 & 0.500 & -0.57 & -1.93 \\
\hline
\end{tabular}

Source: Questionnaire survey 


\section{Conclusions}

Social and environmental responsibilities are of strategic relevance for mining activities. As Esteves (2008) states, it is important that companies have a clear understanding of the issues affecting sustainability in the local communities. During the last two decades, society has become more concerned about these topics, and this has forced companies to redefine their strategy. As a result, sustainable development and ethical management have been included in the corporate policies.

This paper has examined the diffusion of CSR practices, procedures and measurement systems within the aggregate and ornamental stone mining in Catalonia. To sum up, in Catalonia, companies in the surface mining industry are small or middle sized, like most companies in Europe. But this does not stop them from implementing management systems. The number of registered companies increases because of the regulatory pressure in areas such as occupational health and safety and environmental management. Most companies realize the benefits of having a management system while others do not see the reasons to implement them or fear the difficulties.

Mining companies have heard of CSR (around $63 \%$ of the companies were familiar with CSR management systems) and many of them have undertaken some actions, especially in relation with the environment. Nevertheless, the number of companies that adopt CSR procedures and measurement systems is very low, and the diffusion of sustainable mining standards is relatively sparse. Around half of the surveyed companies did not have either written CSR procedures or measurement systems to track the CSR results and only one company has a CSR management system, which constitutes a very low rate of implementation taking into account that in Spain there is 
national standard UNE 22480 especially created for mining activities (about 52\% admitted that they did not know about it).

Findings highlight commitment to CSR: mining companies engage with stakeholders and have implemented different CSR practices oriented to promote the organization's environmental and ethical behavior.

Mining companies in the sample understand the negative impact of their activities on the environment and they want to observe the law and collaborate with both internal and external stakeholders. For these reasons they have implemented several CSR practices.

It is observed that the implementation degree of environmental practices in internal processes is superior to social actions. This result can be attributed to the impacts generated by surface mining on the environment, which constitute the most perceived threats of mining activities. Cooperation with non-governmental organizations was the least frequent activity.

The results obtained in the study show that companies with a higher number of CSR practices had implemented more CSR procedures. Moreover, companies with the highest percentages of CSR procedures implementation also described the highest levels of CSR measurement systems application, and perceived the CSR utility as slightly better. Generally, aggregate mining companies had higher percentages of CSR practices, procedures and measurement systems application than ornamental stone quarries.

Consequently, management of CSR activities may be widely improved. In this sense, the promotion of management systems for sustainable mining might enhance the formalization of CSR activities. We expect that if the diffusion of CSR practices increases, the formalization and systematization of CSR management will be enhanced. 
In conclusion, several CSR practices are possible in mining activities, even in small companies. CSR may improve the image of mining companies and help them improve the way they perform their operations. Although companies that have implemented CSR practices are satisfied with the results and even admit that CSR pays off, there is still a lack of information and therefore the support of the government and professional associations seems necessary to impulse the adoption of such practices. Since companies are used to management systems, this might contribute to the diffusion of CSR management systems and hence the formalization of CSR practices.

\section{References}

Azapagic, A., 2004. Developing a framework for sustainable development indicators for the mining and minerals industry. Journal of Cleaner Production 12, 639662.

Banks, G., 2006. Mining, social change and corporate social responsibility: Drawing lines in the Papua New Guinea mud. Globalisation, Governance and the Pacific Islands, 259-274.

Blinker, L.R., 2009. Mining and the Natural Enviornment. UNCTAD, series of papers on Mining, Environment and Development n6, UNCTAD.

Brown, A.T., Van der Wiele, T., Loughton, K., 1998. Smaller enterprises' experiences with ISO 9000. International Journal of Quality \& Reliability Management $15,273-285$.

Casadesus, M., Marimon, F., Heras, I., 2008. ISO 14001 diffusion after the success of the ISO 9001 model. Journal Of Cleaner Production 16, 1741-1754. 
CEC (Comission of the European Communities), 2000. Promoting sustainable development in the EU non-energy extractive industry. Communication from the Comission, $\operatorname{COM}(2000) 265$ final 3.5, Brussels.

Cowell, S.J., Wehrmeyer, W., Argust, P.W., Robertson, J.G.S., 1999. Sustainability and the primary extraction industries. Resources Policy 25, 277-286.

Deegan, C., Rankin, M., 1996. Do Australian companies report environmental news objectively? An analysis of environmental disclosures by firms prosecuted successfully by Environmental Protection Authority. Accounting, Auditing \& Accountability Journal 9, 50-67.

Dorian, J.P., Humphreys, H.B., 1994. Economic impacts of mining: a changing role in the transitional economies. Natural Resources Forum 18, 17-29.

Elkington, J., 1997. Cannibals with Forks: the Triple Bottom Line of $21^{\text {st }}$ Century Business, New Society Publishers, Oxford.

Escanciano, C., Fernández, B., Suárez, A., 2010. Organización de la actividad preventiva y gestión de la seguridad y salud laboral en la minería española: experiencia de las empresas certificadas ISO 9001. Dirección y Organización 40, 86-98.

Esteves, A.M., 2008. Mining and social development: Refocusing community investment using multi-criteria decision analysis. Resources Policy 33, 39-47.

European Comission. 2011. Sustainable and responsible business. Corporate Social Responsibility $\quad$ (CSR); $\quad$ http://ec.europa.eu/enterprise/policies/sustainablebusiness/corporate-social-responsibility/index_en.htm [Acces: September, 29, 2011]

Evangelinos, K.I., Oku, M. 2006. Corporate environmental management and regulation of mining operations in the Cyclades, Greece. Journal of Cleaner Production $14,262-270$. 
Fernández Fernández, J.L., Melé, D. 2005. From a Paternalistic Past to Sustainable Companies. In: Habisch, A.; Jonker, J.; Wegner, M.; Schmidpeter, R. (Eds.). Corporate Social Responsibility Across Europe, Springer, Berlin, 289-302.

General Directorate of Mining, 2000-2009. Mining statistics, Spain; www.mityc.es/energia/mineria [Acces: September, 29, 2011]

Gibson, R., 2000. Favouring the higher test: contribution to sustainability as the central criterion for reviews and decisions under the Canadian enviornmental assessment act. Journal of Environmental Law and Practice 10, 39-54.

Hamann, R., 2004. Corporate social responsibility, partnerships and institutional change: The case of mining companies in South Africa, Natural Resources Forum 28, 278-290.

Hamann, R., Kapelus, P., 2004. Corporate social responsibility in the mining in Southern Africa: Fair accountability or just greenwash?. Development 47, 85-92.

Harris, N., 2007. Corporate engagement in processes for planetary sustainability: understanding corporate capacity in the non-renewable resources extractive sector, Australia. Business Strategy and the Environment 16, 538-553.

Hilson, G., 2002. An overview of land use conflicts in mining communities. Land Use Policy 19, 65-73.

Hilson, G., Murck, B., 2000. Sustainable development in the mining industry: clarifying the corporate perspective. Resources Policy 26, 227-238.

Howitt, R., 2001. Rethinking resource management: Justice, sustainability and indigenous people, Routledge, London. 
Humphreys, D., 2001. Sustainable development: can the mining industry afford it?. Resources Policy 27, 1-7.

ICMM., 2005. Reporting against the ICMM Sustainable Development Principles. International Council on Mining and Metals, London, pp. 18.

ISO, 2010. ISO 26000:2010. Guidance on social responsibility, International Organization for Standardization, Geneve.

Jenkins, H., 2004. Corporate Social Responsibility and the mining industry: conflicts and constructs. Corporate Social Responsibility and Environmental Management 11, 23-24.

Jenkins, H., Yakovleva, N., 2006. Corporate social responsibility in the mining industry: Exploring trends in social and environmental disclosure. Journal of Cleaner Production 14, 271-284.

Kapelus, P., 2002. Mining, corporate social responsibility and the "Community": The Case of Rio Tinto, Richards Bay Minerals and the Mbonambi. Journal of Business Ethics 39, 275-296.

Kleine, A., Hauff, M., 2009. Sustainability-Driven Implementation of Corporate Social Responsibility: Application of the Integrative Sustainability Triangle. Journal of Business Ethics 85, 517-533.

Lambert, I., 2001. Mining and sustainable development: considerations for minerals supply. Natural resources forum 25, 275-284.

Liu, X, Anbymozhi, V., 2009. Determinant factors of corporate environmental information disclosure: an empirical study of Chinese listed companies. Journal of Cleaner Production 17, 593-600. 
Malhotra, M.J., Grover, V., 1998. An assessment of survey research in POM: from constructs to theory. Journal of Operations Management 16, 407-425.

Mikesell, R.F., 1994. Sustainable development and mineral resources. Resources Policy 20, 83-86.

Mudd, G.M., 2009. The Environmental sustainabilitynext term of previous termminingnext term in Australia: key mega-trends and looming constraints. Resources Policy 35, 98-115.

Munashinge, M., Shearer, W., 1995. Defining and measuring sustainability: the biogeophysical foundations. The United Nations University and World Bank, Washington DC.

Newbold, J., 2003. Social consequences of mining and present day solutions region II in Chile highlighted. Sustainable Development 11, 84-89.

Nijkamp, P., Rodenburg, C., Verhoef, E., 1990. The adoption and diffusion of environmentally friendly technologies among firms. International Journal Technology Management 17, 421-437.

Ortega, E., 1990. Manual de Investigación Comercial, ed. Pirámide, Madrid.

Pegg, S., 2006. Mining and poverty reduction: Transforming rethoric into reality. Journal of Cleaner Production 14, 376-387.

Sánchez, L., 1998. Industry response to the challenge of sustainability: the case of the Canadian nonferrous mining sector. Environmental Management 22, 521-531.

Sandbroke, R., Mehta, P., 2002. FDI and Environment - Lessons from the Mining Sector. Rapporteurs report from the OECD Global Forum on International Investment, Paris. 
Solomon, F., Katz, E., Lovel, R., 2008. Social dimensions of mining: Research, policy and practice challenges for the minerals industry in Australia. Resources Policy $33,142-149$.

Spence, L.J., 1999. Does size matter? The state of the art in small business ethics. Business ethics: A European Review 8, 163-174.

USGS., 1994 to 2009. Minerals Yearbook.

Van der Veen, P., McMahon, G., 2007. Strategic drivers of the mining industry: from enclave production to industrial clusters. In: Proceedings from the Third International Conference on Sustainable Development Indicators in the Minerals Industry, Milos, Greece.

Vintró, C., Comajuncosa, J., 2010. Corporate Social Responsibility in the Mining Industry: Criteria and Indicators. Dyna 161, 31-41.

Walker, J., Howard, S., 2002. Voluntary codes of conduct in the mining industry. Mining, Minerals and Sustainable Development Project (MMSD), IIED, London.

Warhurst, A., 2001. Corporate citizenship and corporate social investment: drivers of tri-sector partnerships. Journal of Corporate Citizenship 1, 57-73.

WCED, 1987. Our common future: The World Comission On Environment and Development, Oxford University Press, Oxford.

Wheeler, D., Fabig, H., Boele, R., 2002. Paradoxes and dilemmas for stakeholder responsive firms in the extractive sector: lessons from the case of Shell and the Ogoni. Journal of Business Ethics 39, 297-318. 
Worrall, R., Neil, D., Brereton, D., Mulligan, D., 2009. Towards sustainability criteria and indicators framework for legacy mine land. Journal of Cleaner Production $17,1426-1434$.

Yakovleva, N., 2005. Corporate social responsibility in the mining industries, Ashgate Publishing, Hampshire. 